\title{
Loss of Reelin suppresses cell survival and mobility in non-Hodgkin lymphoma
}

\author{
AIXIA DOU* ${ }^{*}$, ZHILUN WANG* ${ }^{*}$ NI ZHANG and JUNLI LIU \\ Department of Hematology, The Second Hospital of Shandong University, Jinan, Shandong 250033, P.R. China
}

Received November 2, 2016; Accepted April 18, 2017

DOI: $10.3892 /$ or.2017.5626

\begin{abstract}
Reelin, a secreted glycoprotein, was recently demonstrated to be involved in the pathogenesis of cancer. However, its oncogenic activities in non-Hodgkin lymphoma (NHL) remain unclear. Therefore, we aimed to evaluate the functional role of Reelin in NHL, and the underlying molecular mechanisms. In the present study, we analyzed Reelin expression in lymphoma tissues and cell lines using immunohistochemistry, immunofluorescence staining, qRT-PCR and western blotting. Then, the expression of Reelin was silenced with short hairpin RNA (shRNA)-expressing plasmid in the NHL cell line A20. The effects of Reelin depletion on cell growth, migration and invasion in vitro were determined by CCK- 8 and Transwell assays. Flow cytometry was used to examine the cell cycle status and cellular apoptosis. Hoechst 33258 fluorescence staining was used to analyze morphologic changes caused by apoptosis. The second messenger, cAMP was analyzed by ELISA. In addition, we used nude mice to evaluate the tumorigenic ability of Reelin. Aberrant upregulated levels of mRNA and protein of Reelin were observed in lymphoma tissues and cell lines. Knockdown of Reelin suppressed lymphoma growth, migration and invasion ability of A20. Furthermore, Reelin depletion induced cell cycle arrest in G0/G1 phase and promoted apoptosis of A20 cells. Further analysis indicated that knockdown of Reelin downregulated the expression of CDK5 and IL-10 and activated caspase-3 in shReelin group. ELISA assay showed cAMP at a lower level in shReelin group. SQ22536, a cAMP pathway inhibitor, treated A20 cells and revealed likely effects. The tumor size in a mouse model injected shReelin was significantly smaller than controls. There results suggest that Reelin played essential roles in the development of lymphoma and might be a potential drug target in lymphoma.
\end{abstract}

Correspondence to: Dr Aixia Dou, Department of Hematology, The Second Hospital of Shandong University, 247 Beiyuan Street, Jinan, Shandong 250033, P.R. China

E-mail: douax0110@163.com

*Contributed equally

Key words: lymphoma, Reelin, proliferation, apoptosis, cAMP

\section{Instruction}

Non-Hodgkin lymphoma (NHL) is thought as the most common hematologic malignancy arising from lymphatic cells worldwide (1). Approximately $90 \%$ of lymphoma patients have non-Hodgkin lymphoma (NHL). Most NHL patients have a B-cell type of NHL (85\%) and the other have a T-cell type or an NK-cell type of NHL (2-4). In younger patients, the most common subtypes of NHL are Burkitt lymphoma, diffuse large B-cell lymphoma, lymphoblastic lymphoma, primary mediastinal B-cell lymphoma and anaplastic large cell lymphoma $(2,5,6)$. NHL often arises from genetic alterations such as gene translocations. It has been found that translocation of MYC oncogene on chromosome 8 with IGH gene on chr14, 22 or 2 in adolescents Burkitt lymphoma patients (7). In diffuse large B-cell lymphoma, aberrant increased incidence of MYC translocation and MYC expression and higher incidence of BCL2 translocations have also been observed (7). PMBL (primary mediastinal large B cell lymphoma) and nodular sclerosis Hodgkin lymphoma have biological features of expression of the CD30 antigen (8). Several checkpoint inhibitors are used for immune checkpoint blockade and other immune therapies such as pidilizumab, nivolumab and pembrolizumab (9). These reports still are not enough to explain the pathogenesis of NHL. Therefore, new molecular biomarkers of NHL and its mechanism need to be further explored.

Reelin, also known as RELN, is a $420-\mathrm{kDa}$ secreted extracellular glycoprotein which is involved in regulation of neuronal migration during the process of brain development (10-12). Reelin guides neuron migration by interacting with two cell surface receptors, VLDLR (very low density lipoprotein receptor) and ApoER2 (apolipoprotein E receptor 2) and by activating downstream signaling pathway which instructs neurons to reach the proper laminar position in cortex (13). Most studies focused on the function of Reelin in neural system development. Interestingly, it has been reported that Reelin is aberrantly expressed in various cancer tissues, including esophageal, pancreatic, prostate, breast cancer and mouse medulloblastoma (14-18). Expression of Reelin was associated with high-grade prostate cancer (17). These are some controversial reports. Epigenetic silence of Reelin was related to poor outcomes of gastric and pancreatic cancer $(14,19)$. Epigenetical controlled loss of Reelin is involved in the poor prognosis of breast cancer (18). 
Mutation and expression spectrum of adult T-ALL (T-cell acute lymphoblastic leukemia) revealed aberrant expression level of Reelin (20). Silence of Notch1 results in downregulation of glutamatergic transmission and leads to inhibition of cAMP signaling pathway. cAMP intracellular level depends on synthesis by adenylate cyclase and cAMP participate in the Notch1 mediated downstream signaling pathway. The mechanism of Reelin in cancer is still unclear and we assume that function of Reelin is associated with cAMP signaling pathway.

In the present study, we detected the differential expression of Reelin in normal lymph and lymphoma and altered the expression of Reelin to explore the function in cell proliferation, migration and invasion and apoptosis in vitro and in vivo, as well the underlying molecular mechanism in NHL.

\section{Materials and methods}

Tissue samples. Fresh samples from NHL and corresponding normal injury induced lymphoid tissue were obtained from patients after informed consents at the Department of Pathology, the Second Hospital of Shandong University. The research was conducted with the approval of the Ethics Committee of the Second Hospital of Shandong University. The samples were stored at $-80^{\circ} \mathrm{C}$.

Cell culture, transfection and treatment. The mouse B cell lymphoma cell line A20 (\#0046; Hongshun, Shanghai, China), and normal lymphocyte cell lines were purchased from the American Type Culture Collection (ATCC; Manassas, VA, USA). The two cell lines were cultured in RPMI-1640 medium (Invitrogen, Carlsbad, CA, USA) supplemented with $90 \%$ $0.05 \mathrm{mM} 2$-mercaptoethanol and $10 \%$ fetal bovine serum (FBS). Both of the cell lines were incubated in a humidified aseptic condition at $37^{\circ} \mathrm{C}$ with $5 \% \mathrm{CO}_{2}$.

Knockdown of Reelin in A20 cells was performed by lipofection transfection. The plasmid vectors containing short hairpin RNA (shRNA) for Reelin (shReelin) and the corresponding negative control (NC) were obtained from Thermo Fisher Scientific (Waltham, MA, USA). Quantitative real-time PCR (qRT-PCR) and western blotting were performed to analyze the expression of Reelin. Adenylate cyclase (AC) inhibitor SQ22536 were purchased from Selleck Chemicals (Houston, TX, USA). All the cells were cultured in SQ22536 (1x10-5 $\mathrm{mol} / \mathrm{l}$ ) for signaling inhibition.

$R N A$ extraction and $q R T-P C R$. Total RNA was extracted from cells and fresh tissues using TRIzol (Takara Bio, Tokyo, Japan) according to the manufacturer's instructions. After reverse transcription using qPCR Bestar ${ }^{\circledR}$ SYBR-Green kit (DBI, Shanghai, China), qRT-PCR was performed using SYBRGreen method. Primers for GAPDH: F, 5'-TGTTCGTCATGG GTGTGAAC-3' and R, 5'-ATGGCATGGACTGTGGTCAT-3'. Primers for Reelin: F, 5'-AAGGGAGAAGAAACTGAGAA GC-3' and R, 5'-TGGGAAGGTCGTGACTGAAA-3'. Primers for CDK5: F, 5'-GTCGTGCCCAAACTCAATG-3' and R, 5'-GCGGACAGAAGTCGGAGAA-3'. Primers for IL-10: F, 5'-AGAACCAAGACCCAGACATCA-3' and R, 5'-GCAT TCTTCACCTGCTCCAC-3'. Primers for caspase-3: F, 5'-TG
GTTCATCCAGTCGCTTTG-3' and R, 5'-AATTCTGTGCC ACCTTTCG-3'. The total volume was $20 \mu \mathrm{l}$ and the reaction system as follow: Bestar ${ }^{\circledR}$ SYBR-Green qPCR Master Mix $10 \mu \mathrm{l}$, PCR forward primer $(10 \mu \mathrm{M}) 0.5 \mu \mathrm{l}$, PCR reverse primer $(10 \mu \mathrm{M}) 0.5 \mu \mathrm{l}$, cDNA $1 \mu \mathrm{l}$, $\mathrm{ddH}_{2} \mathrm{O} 8 \mu \mathrm{l}$. The qRCR procedure was: initial denaturation at $94^{\circ} \mathrm{C}$ for $2 \mathrm{~min}$, denaturation at $94^{\circ} \mathrm{C}$ for $20 \mathrm{sec}$, annealing extension at $58^{\circ} \mathrm{C}$ for $20 \mathrm{sec} 40$ cycles was performed on Agilent Stratagene Real-Time PCR platform (Mx3000P). The absorbance value was then detected. The evaluation of samples was performed three times and the fold-change of gene expression was calculated by the $2^{-\Delta \Delta C T}$ method.

Western blotting. Total protein was extracted in lysis buffer and quantified using the BCA method (\# 23227, Pierce BCA protein assay kit; Thermo Fisher Scientific). Proteins were separated on $10 \%$ SDS-PAGE and transferred to PVDF (polyvinylidene fluoride) membranes (Millipore, Billerica, MA, USA). After incubation with antibodies (Reelin: 1:5,000; Sigma-Aldrich, St. Louis, MO, USA; CDK5: 1:1,000; Sigma-Aldrich; IL-10: 1:1,500; Sigma-Aldrich; caspase-3: 1:1,000; Sigma-Aldrich), the membranes were washed and incubated with HRP goat anti-rabbit IgG (\#BA1054, 1:20,000; Wuhan Boster Biological Technology, Ltd., Wuhan, China) or HRP goat anti-mouse IgG (\#BA1051, 1:20,000; Wuhan Boster Biological Technology) for $40 \mathrm{~min}$. Densitometric analysis was performed on the autoradiograms and relative protein levels were quantified using ImageJ.

$H \& E$ staining. Tumor specimens were fixed and cut into 4- $\mu$ m-thick slices. The sections were deparaffinized in xylene and rehydrated in graded alcohol. The sections were stained using Hematoxylin and Eosin Staining kit (\#C0105; Beyotime Institute of Biotechnology, Shanghai, China). Nuclear and ribosome were stained blue and cytoplasm was stained red.

Immunohistochemistry. Tumor specimens were fixed and cut into $4-\mu \mathrm{m}$-thick slices. The tumor and normal tissues sections were deparaffinized in xylene and rehydrated in graded alcohol. The sections were incubated with nonimmune serum after being boiled in $0.01 \mathrm{M}$ citrate buffer for 2 min. Immunostaining was performed using DAB Plus kit (Fuzhou Maixin Biotechnology, Co., Ltd., Fuzhou, China) after incubating in Reelin human or mouse antibody (1:5,000; Sigma-Aldrich) at $4^{\circ} \mathrm{C}$ overnight.

Immunofluorescence staining. The cell lines grown on coverclips were washed with cold phosphate-buffered saline (PBS) and fixed with methanol/acetone for $10 \mathrm{~min}$. After washing with PBS three times, the cells were blocked with $2 \%$ serum in PBS for $40 \mathrm{~min}$. Then the cells were incubated with Reelin antibody (Sigma-Aldrich), followed by staining with FITC conjugated secondary antibodies. Finally, cells were double stained with DAPI and images were collected by a laser scanning confocal microscopy.

Cell proliferation assay. Cell Counting kit-8 (CCK-8; Dojindo Laboratories, Kumamoto, Japan) was used to detect cell proliferation according to the guidance of the product 
instructions. The cell lines were cultured for six overnight and CCK-8 liquids were added to the medium at time-points of 0 , 24,48 and $72 \mathrm{~h}$ for $1-2 \mathrm{~h}$ each time. The absorbance of cells was measured at $450 \mathrm{~nm}$ with the microplate reader (Thermo Fisher Scientific).

Transwell assay. Transwell assay was performed to measure the invasion ability with $8-\mu \mathrm{m}$ pore membrane filter chamber kit (Corning, Inc., Corning, NY, USA). After infection with plasmid vectors for $48 \mathrm{~h}$, the cells were resuspended with serum-free medium and the bottoms were filled with complete medium with $10 \%$ FBS. After $24 \mathrm{~h}$, the chambers were fixed with methyl alcohol and strained with $800 \mu \mathrm{l}$ Giemsa, transmembraned cells were stained using 4'6-diamidino2-phenylindole dye and counted under a fluorescence microscope to count the cell numbers.

Flow cytometry assay. The effect of Reelin depletion on cell cycle progression was determined by flow cytometric analysis of cells incubated with PI staining according to the manufacturer's instructions. Cell apoptosis analysis was performed using Annexin V and PI double staining. Briefly, the cells were harvested when the density reach to $80 \%$ and then fixed in $75 \%$ ice-cold ethanol for 1 day. After being washed with cold PBS, the collected cells were stained with $500 \mu \mathrm{l}$ PI buffer (propidium iodide, \#C1052; Beyotime Institute of Biotechnology) for $1 \mathrm{~h}$ in $37^{\circ} \mathrm{C}$ in the dark to analyze cell cycle distribution. The collected cells were stained by $5 \mu \mathrm{l}$ Annexin V-APC and $5 \mu \mathrm{l}$ PI to detect apoptosis for $15 \mathrm{~min}$ in the dark. The suspension cells were filtered and were analyzed by a flow cytometer (FACSCalibur; BD Biosciences, San Jose, CA, USA).

Hoechst 33258 staining. The A20-shReelin cells and A20-NC cells were stained using Hoechst 33258 . The cells were fixed in fixing solution for $10 \mathrm{~min}$ and subsequently washed twice using PBS. The cells were then stained in Hoechst 33258 solution for 5 min and washed in PBS twice. The images were collected by fluorescence microscope.

ELISA for cAMP. To investigate the content of cAMP in the supernatants, ELISA was performed in A20 cells. Briefly, A20 cells treated with shReelin or SQ22536 were seeded in 6-well plates. The plates were incubated in $50 \mu \mathrm{l} /$ well PBS with $1 \%$ BSA, and the supernatants were collected to detect the concentration of cAMP according to the manufacturer's instructions.

$B A L B / c$ mouse model. A20 cell lines were cultured and infected shReelin and NC. Stable transfected cell lines of two groups were cultured under the treatment of G418. Cells $\left(2 \times 10^{6}\right)$ were injected into BALB/c mice (5-weeks old, 6 mice per group). After 30 days, the tumor tissues were collected to perform detection. The size of tumor in mice were measured as the long diameter (a) and short diameter (b) every two days, the average diameter $=(a+b) / 2(21)$. The average diameters were collected for evaluate the tumor size.

Statistical analysis. The Graphpad Prism was used to analyze the related data. All data were expressed as mean \pm SD of at least three independent assays, each one was performed in triplicate. The difference was evaluated

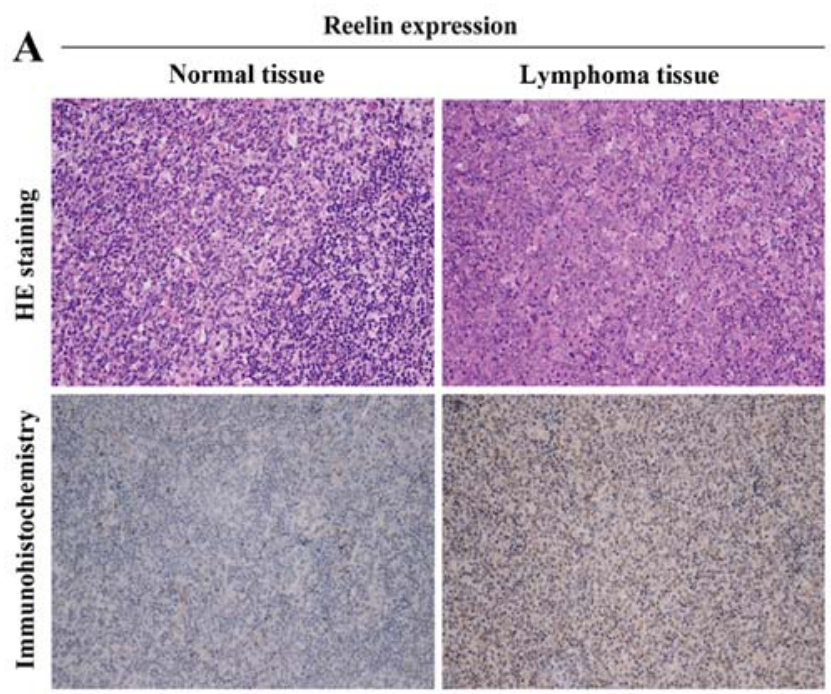

B
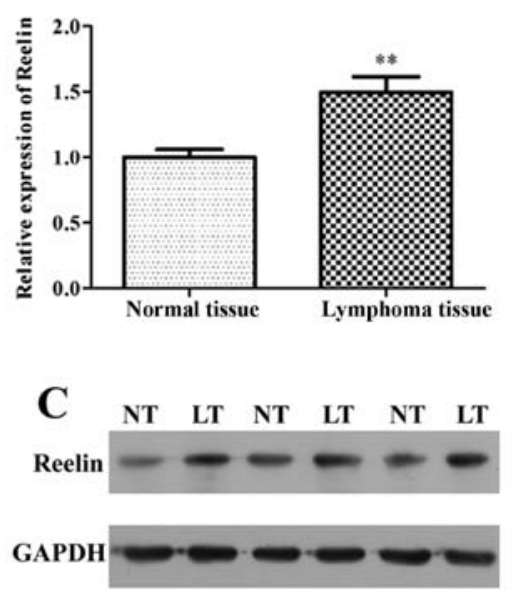

Figure 1. Expression of Reelin in human lymphoma tissues. (A) H\&E staining and immunohistochemistry of Reelin in human normal tissue and lymphoma tissue. Reelin was overexpressed in lymphoma tissue. (B) The mRNA expression of Reelin was significantly expressed in lymphoma tissue. (C) The protein expression of Reelin had a higher level in lymphoma tissue than normal tissue. ( ${ }^{* *} \mathrm{P}<0.01$; NT, normal tissue, LT, lymphoma tissue).

using the Student's t-test and $\mathrm{P}<0.05$ was considered statistically significant.

\section{Results}

Reelin was highly expressed in human NHL tissue and cell lines. To investigate the role of Reelin in NHL, the expression of Reelin was first determined in lymphoma tissue and normal tissue using $\mathrm{H} \& \mathrm{E}$ staining and immunohistochemistry assays. As depicted in Fig. 1A, we found that Reelin showed positive cytoplasmic and nuclear immunostaining in tumor tissues. Furthermore, the mRNA expression of Reelin in lymphoma tissue was significantly higher than that in normal tissue (Fig. 1B; P<0.01). The results of western blotting revealed that the protein level of Reelin was also elevated in lymphoma tissue (Fig. 1C). Collectively, it suggested that aberrant higher expression of Reelin occurred in lymphoma tissue comparing to the normal tissue. 
A

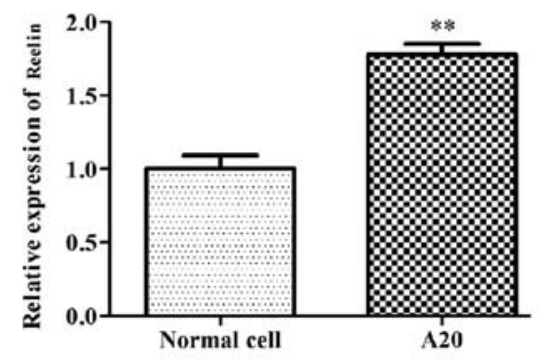

C
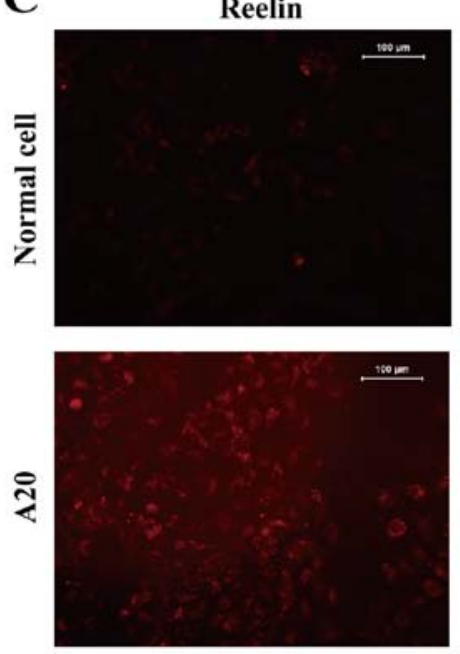

B

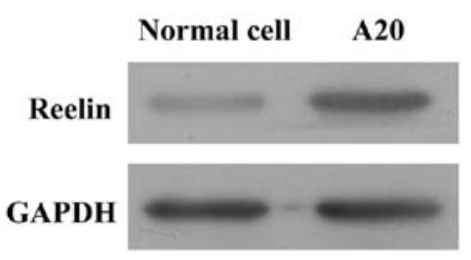

DAPI
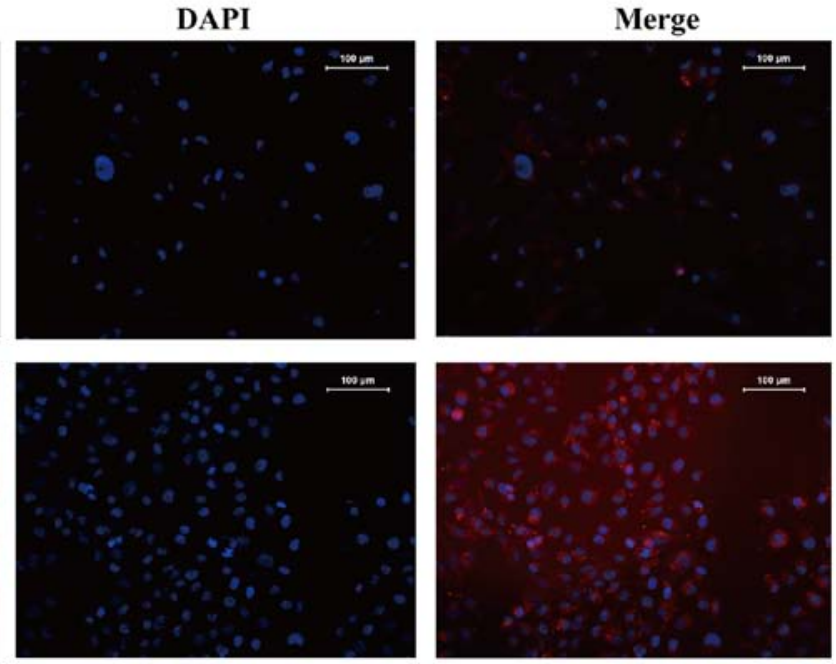

Figure 2. Expression of Reelin in normal lymphocyte cells and A20 cells. (A) The mRNA expression of Reelin was significantly suppressed in normal lymphoma cells. (B) The protein expression of Reelin had a higher level in A20 than normal lymphocyte cells. (C) Microscopic images of Reelin localization in normal lymphocyte cells and A20 cells. GAPDH was used as an internal control. ${ }^{* *} \mathrm{P}<0.01$.

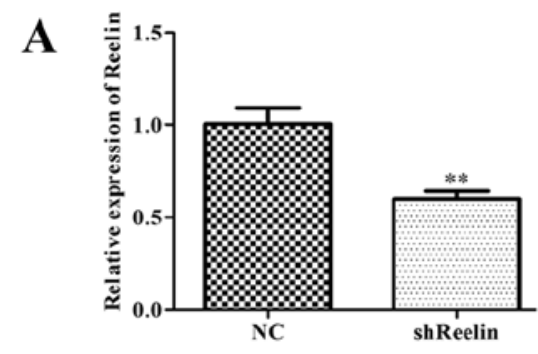

$\mathrm{NC}$

D

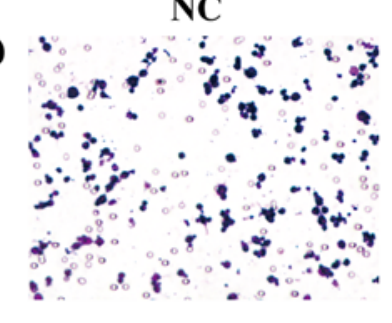

$\mathbf{E}$

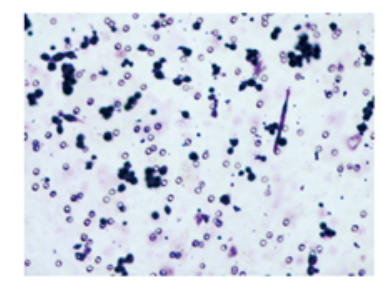

B

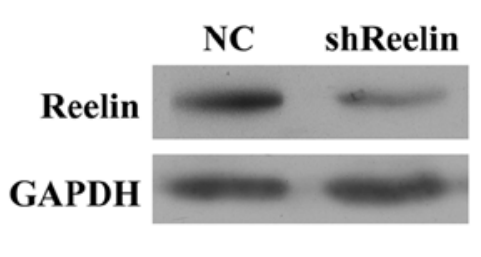

shReelin
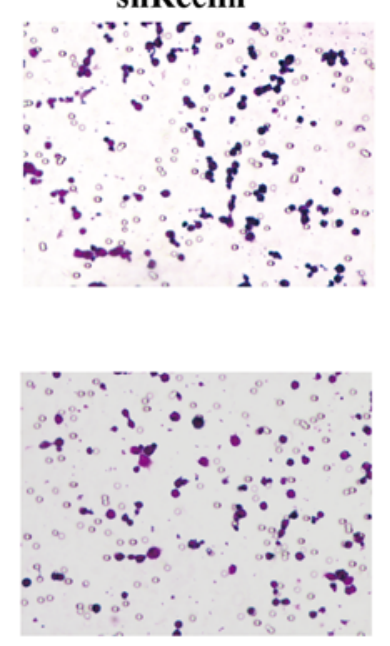

C
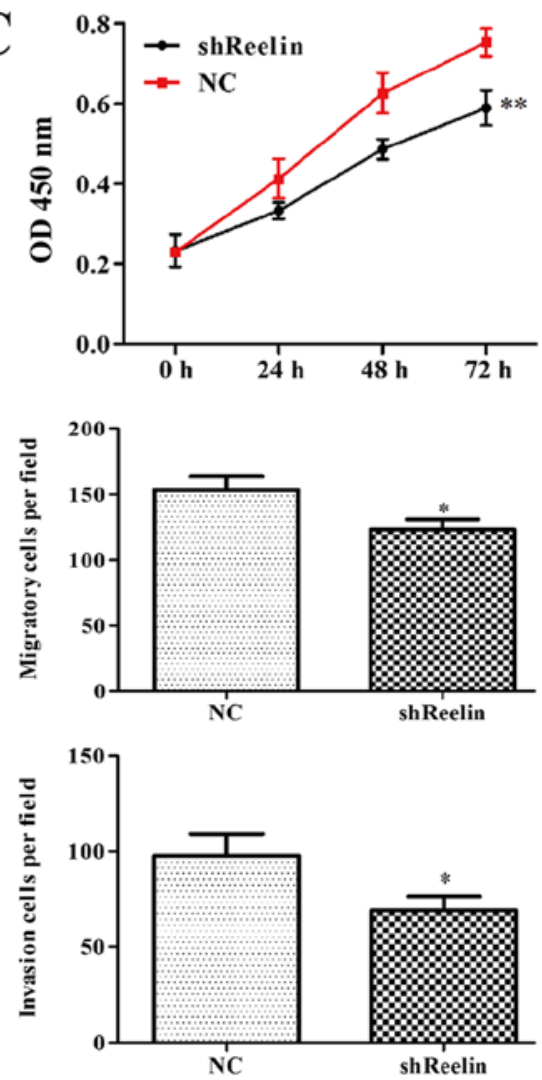

Figure 3. Knockdown of Reelin suppresses cell growth, cell migration and invasion. (A and B) Expression analysis of Reelin in A20 cells infected with shReelin by real-time PCR and western blotting. (C) Cell growth curve of A20 infected shRNA-NC cells and shReelin. Knockdown of Reelin suppressed the growth of A20 cell lines. (D and E) Transwell assay showed that migration and invasion of A20 infected shReelin were inhibited. ( $\left.\mathrm{P}<0.05{ }^{* *} \mathrm{P}<0.01\right)$. 
A

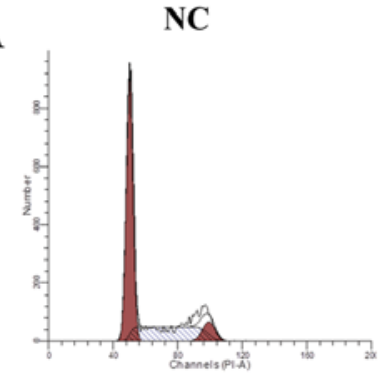

B
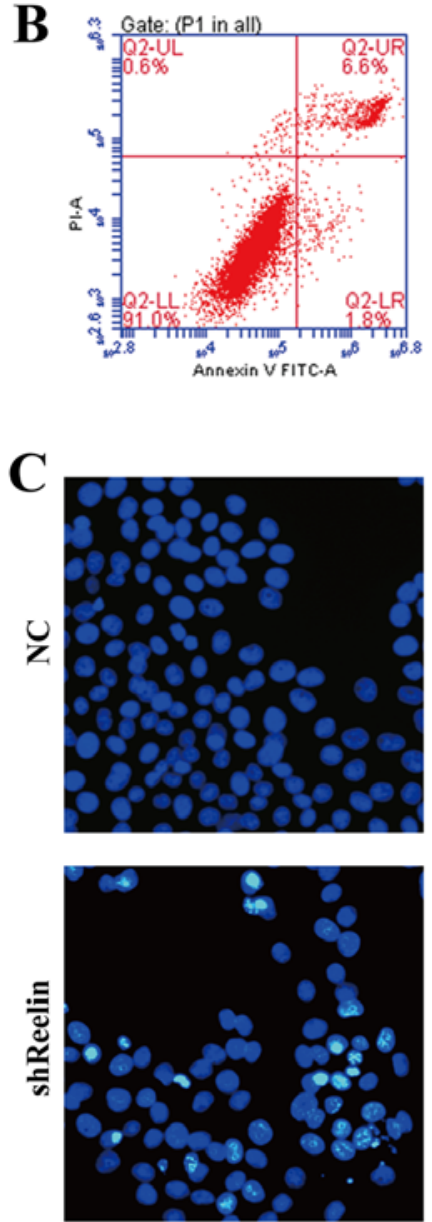

shReelin
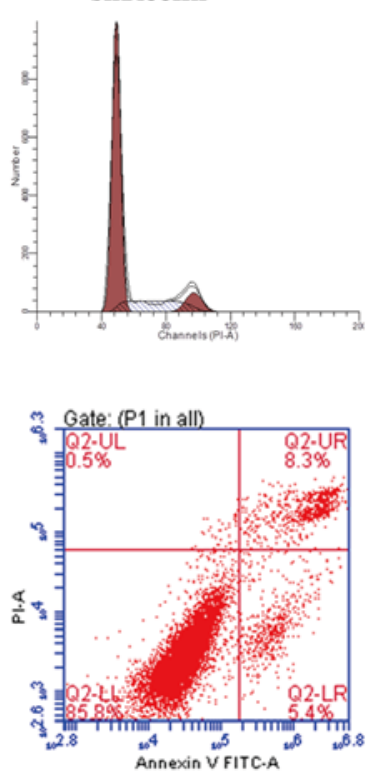

D

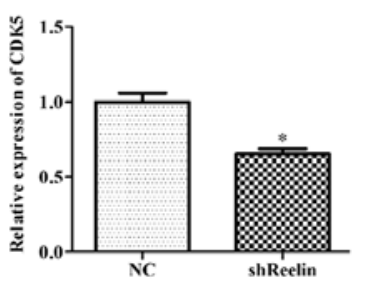

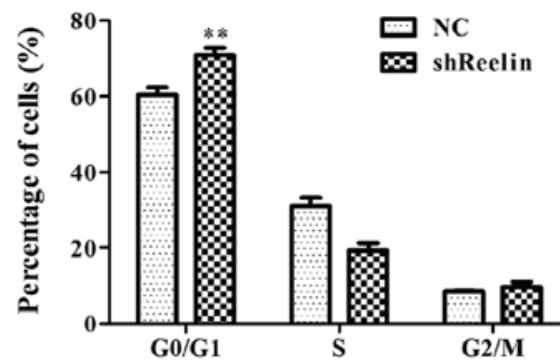

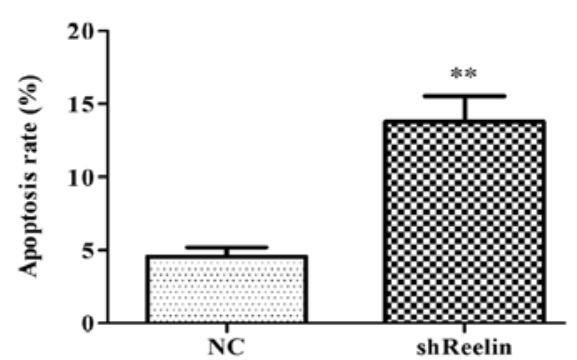

Figure 4. Knockdown of Reelin induces cell cycle arrest and apoptosis. (A) Cell cycle analysis of A20 infected cells with shRNA-NC and shReelin by flow cytometry. (B) Apoptosis of A20 cells detected by Annexin V/PI double staining. (C) Hoechst staining. (D) The mRNA levels of CDK5, caspase-3 and IL-10 in A20 cells using real-time PCR analysis infected with shReelin. (E) The protein level of CDK5, caspase-3 and IL-10 in A20 cells infected with shReelin using western blot analysis; (F) ELISA assay was used to determine the concentration of cAMP in A20 cells infected with shReelin. ${ }^{*} \mathrm{P}<0.05 ;{ }^{* *} \mathrm{P}<0.01$.

To address the expression of Reelin in the lymphoma A20 cell line was used to detect the mRNA level using RT-PCR and protein level in western blotting. The mRNA expression of Reelin was increased in A20 cells (1.78 \pm 0.07$)$, as compared with normal cells $(1.00 \pm 0.09)$ (Fig. $2 \mathrm{~A} ; \mathrm{P}<0.01)$. Similarly, the protein expression of Reelin (Fig. 2B) was markedly higher than that of the normal cells. The immunofluorescence staining showed that Reelin protein mainly located in the cell cytoplasm and presented a higher level expression than that of normal cells (Fig. 2C). Taken together, Reelin might play an important role in the progression of lymphoma.

Inhibition of Reelin suppressed lymphoma cell proliferation, migration and invasion. To further investigate the biological behavior of Reelin in lymphoma, the expression of Reelin was downregulated in the A20 cells using RNA interference. The results of qRT-PCR indicated that the mRNA level of Reelin was significantly reduced by $43 \%$ in shReelin group (Fig. 3A). Consitently, the protein level of Reenlin was also obviously downregulated in A20 cells infected with shReelin (Fig. 3B). These results suggested stably Reelin-silenced A20 cells were successfully constructed.

To better understand the role of Reelin in NHL, we examined the variation tendency of cell proliferation after infection with shReelin or NC using MTT assay. As shown in Fig. 3C, the growth curve of shReelin-infected cells was remarkably lower than that of controls $(\mathrm{P}<0.01)$. In addition, the Transwell assay results showed the number of migratory A20 cells was 

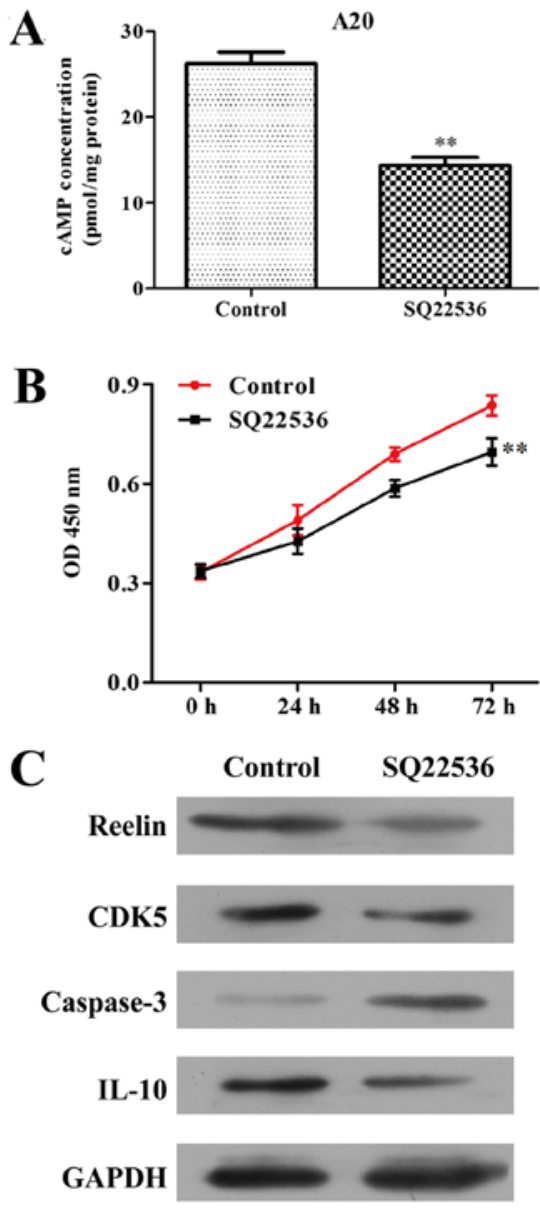

Figure 5. Effects of AC inhibitor SQ22536 on A20 cell proliferation and expression of cAMP, Reelin, CDK5, IL-10 and caspase-3. (A) The expression level of cAMP in A20 cells treated with SQ22536 using ELISA assay. (B) The proliferation rate analysis of A20 cell treated with SQ22536 using CCK-8 assay. (C) Western blotting determined the expression levels of Reelin, CDK5, caspase-3 and IL-10 in A20 treated with SQ22536. ${ }^{* *} \mathrm{P}<0.01$.

markedly decreased from $154 \pm 12$ in shReelin treated group to $118 \pm 9$ in NC group (Fig. 3D; P<0.05). The invasion ability of shReelin group was also significantly decreased after Reelin knockdown in A20 cells (Fig. 3E; P<0.05). Collectively, above data indiate that Reelin prominently favors cell proliferation, migration and invasion in lymphoma.

Inhibition of Reelin induces cell cycle arrest and apoptosis. To determine whether downregulation of Reelin inhibited cell proliferation via direct regulation of cell cycle or apoptosis, we evaluated the distribution of cell cycle and apoptosis of A20 infected with shReelin using flow cytometry assay. As shown in Fig. 4A, the percentage of cells in G0/G1 phase remarkably increased in shReelin group $(70.9 \pm 1.95)$, when compared with NC groups (60.39 \pm 1.96$)$, suggesting cell cycle was arrested in $\mathrm{G} 0 / \mathrm{G} 1$ phase induced by shReelin $(\mathrm{P}<0.01)$. Moreover, we found knockdown of Reelin obviously promoted overall cell apoptosis in A20 cells (Fig. 4B, $\mathrm{P}<0.01, \mathrm{NC}$ group, $4.57 \pm 0.37$;

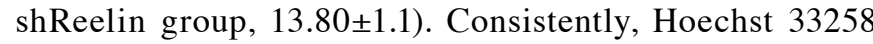
staining revealed obvious decrease in the nuclei of live cells (blue color) (Fig. 4C) in A20 cells infected with shReelin. Our data strongly suggest that knockdown of Reelin has anticancer potential by inducing cell cycle arrest and apoptosis.
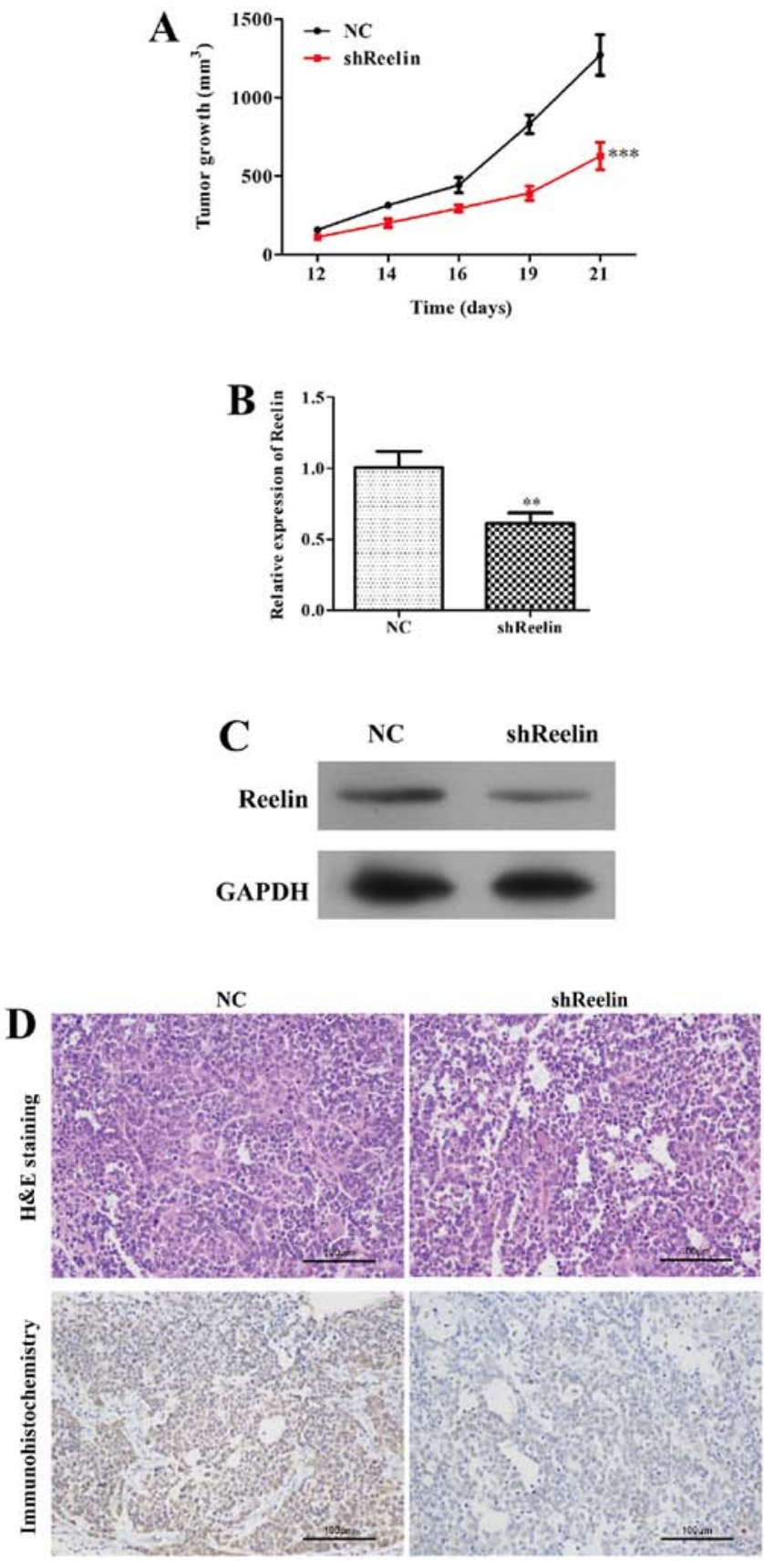

Figure 6. Effects of Reelin silencing on the tumorigenesis of NHL in vivo. (A) Changes in the tumor volume on the day 12, 14, 16, 19 and 21 after the A20 cells were implanted subcutaneously into the BALB/c mouse model. (B) The mRNA expression level of Reelin in tumor tissues collected from mice using real-time PCR analysis. (C) The protein level of Reelin in tumor tissues collected from mice using western blot analysis. (D) Representative immunohistochemistry results are shown. ${ }^{* * *} \mathrm{P}<0.01,{ }^{* * * *} \mathrm{P}<0.001$.

Furthermore, we investigated the regulatory mechanism of Reelin in A20 cells using qRT-PCR and western blot assays. As shown in Fig. 4D, the mRNA levels of CDK5 (NC group, $1.00 \pm 0.06$; shReelin group, $0.65 \pm 0.04$ ) and IL-10 (NC group, $1.00 \pm 0.11$; shReelin group, $0.62 \pm 0.04$ ) were signficantly reduced in A20 cells infected with shReelin. Moreover, knockdown of Reelin obviously upregulated the mRNA level of caspase-3 (NC group, 1.00 \pm 0.1 ; shReelin group, 1.37 \pm 0.12 ) in A20 cells. Similar trends of Reelin protein levels were observed in both shReelin group and $\mathrm{NC}$ group by western blot analysis 
(Fig. 4E). In addition, ELISA was performed to measure the concentration of intracellular second messenger cAMP. The results showed that intracellular level of cAMP was significantly decreased in Reelin knockdown (Fig. 4F, P<0.05, NC

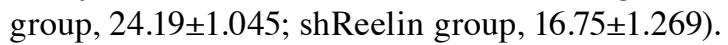

Effects of adenylate cyclase (AC) inhibitor on lymphoma cell proliferation. It was previously shown that increased cAMP could elevate the level of cyclin $E$ and activate the MEK/ERK pathway (22), suggesting it might play an important role in regulating cell cycle progression and apoptosis. To clarify the effects of cAMP level on A20 cells, its intracellular level was strongly decreased by $\mathrm{AC}$ inhibitor SQ22536, as confirmed by RT-PCR analysis (Fig. 5A, NC group, 26.23 \pm 0.7636 ; shReelin group, 14.33 \pm 0.5633 ). CCK-8 assay showed that downregulation of cAMP significantly suppressed cell growth rate in A20 cells compared with that of the controls (Fig. 5B; $\mathrm{P}<0.01$ ). Moreover, cells presented reduced expression of Reelin, CDK5, and IL-10 and elevated expression of caspase-3 after SQ22536 treatment (Fig. 5C), which might all be associated with decreased cAMP levels. Collectively, these findings suggest that activation of Reelin/ cAMP pathway might play a pivotal role in both survival and proliferation of NHL cells.

The lymphoma mouse model. To address the carcinogenicity of Reelin in an animal model, we injected shReelin cells and shRNA-NC cells into 5-week-old BAL/B mice. As shown in Fig. 6A, the volume of tumors was significantly suppressed in mice inoculated with Reelin-silenced A20 cells $(\mathrm{P}<0.05)$, while the size of the mice in control groups was steadily increased during day 12-21. These results were confirmed by analysis of expression of Reelin in tissue of xenograft murine model using qRT-PCR, western blot analysis, H\&E staining and immunohistochemistry assays. The expression level of Reelin group was strongly suppressed (Fig. 6B and C,

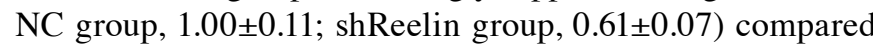
to the NC groups. The number of Reelin positive cells was significantly less in shReelin group than that of control groups (Fig. 6D). These results indicated that Reelin depletion could inhibit NHL tumorigenesis.

\section{Discussion}

NHL constitutes $90 \%$ of lymphoma and causes significant high morbidity and mortality $(2,3)$. The incidence of NHL increases with age and higher in males (23). Although molecular investigators have provided evidence that NHL involves a number of genetic alterations, it is not enough to explain the mechanism of NHL. The treatment of NHL patients is according to the type of NHL, the stage and category of NHL and the patient's overall health. Types of treatment include radiation therapy, stem cell transplantation and drug therapy such as Rituxan, Adcetris, Folotyn, Lstodax, Treanda, Velcade and Zevalin (2-4). Recently, overexpression of Reelin was reported to be associated with poor prognosis and survival in multiple myeloma cells (24). Previous studies also showed that high level of Reelin was correlated with poor outcomes of esophageal cancer and retinoblastoma $(16,25)$. Therefore, we speculated that Reelin might play essential roles in NHL. In the present study, we found Reelin was aberrantly upregulated in lymphoma tissue and cell lines. Therefore, in order to investigate the role of Reelin in NHL, shRNA was used to efficiently downregulate the expression of Reelin. When infected with shReelin, it was observed that A20 have lower proliferation, suppressed invasion and increased apoptosis, together with arrested cell cycle in the G0/G1 phase. Mice bearing tumor analysis further revealed that the size of tumor in mice injected shReelin A20 cells was smaller than that of the controls. These results indicated that Reelin may play prominent roles in regulating NHL cell growth and invasion.

In order to explore the mechanism underlying Reelin may contribute to NHL, we detected the apoptosis markers in the shReelin infected A20 cell lines and control cell lines. In the present study, we found that Reelin, as a secreted extracellular glycoprotein that functions to affect cAMP signaling pathway. cAMP (activating cyclic adenosine monophosphate) is an intracellular second messenger which can activate downstream factor PKA and $\mathrm{NF}-\kappa \mathrm{B}$. These proteins regulate the transcription of apoptotic target genes including Bcl-2 and Bax (26-29). Substantial evidence has shown that cAMP promoted apoptosis of lymphocytes in rats and humans (30-33). In addition, cAMP is involved in the control and development of the inflammatory process and cellular proliferation $(34,35)$. Elevating cAMP suppress $\mathrm{T}$ cell activation, proliferation and production of IL2, IL-12, IFN- $\gamma$ and TNF- $\alpha$ through inhibition of NF- $\kappa \mathrm{B}$ activity (36-38). In cell cycle distribution and apoptosis analysis, more A20 cells infected with shReelin were arrested in the G0/G1 phase and induced apoptosis. We propose that Reelin plays essential roles in cell cycle regulation and apoptosis. In apoptosis process, IL-10 and caspase-3 are major markers. IL-10, as a Th2 cytokine, exerts immunomodulatory capacity and can be induced by cAMP through phosphorylation of CREB (cAMP-response element binding protein) in monocytes $(39,40)$. In A20 cells, knockdown of Reelin downregulated the expression of IL-10 and upregulated the expression of cleaved caspase-3. The evidence indicates that Reelin promotes tumor cell proliferation and inhibits apoptosis. It was reported that Reelin has two major receptors: ApoER2 (apolipoprotein E receptor 2) and NMDAR (N-methyli-D aspartate receptor) to transfer signals. Notch1 could function as a postsynaptic receptor with functional interactions with these two receptors $(41,42)$. Loss of Notch1 results in suppressing glutamatergic transmission and leads to decreased cAMP response element-binding signaling (42). Increased intracellular content of cAMP is closely related with the apoptosis of lymphocytes $(30,31)$. Injection of Reelin increased cAMP-response element binding protein after 15 min and these changes correlated with higher dendritic spine density and hippocampal CA1 LTP (long-term potentiation) in vivo (43). As an intracellular second messenger, cAMP can inhibit NF- $\kappa \mathrm{B}$, which regulates the transcription of downstream apoptotic target genes (26-29). In the present study, secreted cAMP was suppressed in A20 cells infected with shReelin, which indicates Reelin suppresses tumor cell apoptosis through regulating the activity of cAMP. These results further prove that Reelin has carcinogenic function in lymphoma and cAMP signaling pathway inhibitor SQ22536 could be a potential chemotherapy drug for NHL. 
In conclusion, this study demonstrated that knockdown of Reelin could inhibit lymphoma cell proliferation, migration and invasion. Suppressed cell proliferation is closely associated with cell cycle arrest at G0/G1 phase and induced apoptosis. Furthermore, cAMP signaling inhibitor might be a potential therapeutic approach in NHL. Further investigation may help to better understand NHL progression.

\section{Acknowledgements}

The present study is supported by grants from the Shandong Provincial Medical and Health Science and Technology Development Plan (no. 2014WS0159).

\section{References}

1. Siegel RL, Miller KD and Jemal A: Cancer statistics, 2015. CA Cancer J Clin 65: 5-29, 2015.

2. Wang H, Ji X, Liu X, Yao R, Chi J, Liu S, Wang Y, Cao W and Zhou Q: Lentivirus-mediated inhibition of USP39 suppresses the growth of breast cancer cells in vitro. Oncol Rep 30: 2871-2877, 2013.

3. SEER Stat Fact Sheets. NCI2014.

4. Pinnix CC, Smith GL, Milgrom S, Osborne EM, Reddy JP, Akhtari M, Reed V, Arzu I, Allen PK, Wogan CF, et al: Predictors of radiation pneumonitis in patients receiving intensity modulated radiation therapy for Hodgkin and non-Hodgkin lymphoma. Int J Radiat Oncol Biol Phys 92: 175-182, 2015.

5. Pulte D, Jansen L and Brenner H: Survival disparities by insurance type for patients aged 15-64 years with non-Hodgkin lymphoma. Oncologist 20: 554-561, 2015.

6. Rossi C, Jégu J, Mounier M, Dandoit M, Colonna M, DaubisseMarliac L, Trétarre B, Ganry O, Guizard AV, Bara S, et al: Risk assessment of second primary cancer according to histological subtype of non-Hodgkin lymphoma. Leuk Lymphoma 56 2876-2882, 2015.

7. Hochberg J, El-Mallawany NK and Abla O: Adolescent and young adult non-Hodgkin lymphoma. Br J Haematol 173: 637-650, 2016

8. El-Mallawany NK and Cairo MS: Advances in the diagnosis and treatment of childhood and adolescent B-cell non-Hodgkin lymphoma. Clin Adv Hematol Oncol 13: 113-123, 2015.

9. Matsuki E and Younes A: Checkpoint inhibitors and other immune therapies for Hodgkin and non-Hodgkin lymphoma. Curr Treat Options Oncol 17: 31, 2016.

10. Frotscher M: Cajal-Retzius cells, Reelin, and the formation of layers. Curr Opin Neurobiol 8: 570-575, 1998.

11. Groen JL, Ritz K, Jalalzadeh H, van der Salm SM, Jongejan A, Mook OR, Haagmans MA, Zwinderman AH, Motazacker MM, Hennekam RC, et al: RELN rare variants in myoclonus-dystonia. Mov Disord 30: 415-419, 2015.

12. Sommen M, Van Camp G, Liktor B, Csomor P, Fransen E, Sziklai I, Schrauwen I and Karosi T: Genetic association analysis in a clinically and histologically confirmed otosclerosis population confirms association with the TGFB1 gene but suggests an association of the RELN gene with a clinically indistinguishable otosclerosis-like phenotype. Otol Neurotol 35: 1058-1064, 2014.

13. Tissir F and Goffinet AM: Reelin and brain development. Nat Rev Neurosci 4: 496-505, 2003.

14. Sato N, Fukushima N, Chang R, Matsubayashi H and Goggins M: Differential and epigenetic gene expression profiling identifies frequent disruption of the RELN pathway in pancreatic cancers. Gastroenterology 130: 548-565, 2006.

15. Wetmore C, Eberhart DE and Curran T: The normal patched allele is expressed in medulloblastomas from mice with heterozygous germ-line mutation of patched. Cancer Res 60: 2239-2246, 2000.

16. Wang Q, Lu J, Yang C, Wang X, Cheng L, Hu G, Sun Y, Zhang $\mathrm{X}$, Wu M and Liu Z: CASK and its target gene Reelin were co-upregulated in human esophageal carcinoma. Cancer Lett 179: 71-77, 2002.
17. Perrone G, Vincenzi B, Zagami M, Santini D, Panteri R, Flammia G, Verzì A, Lepanto D, Morini S, Russo A, et al: Reelin expression in human prostate cancer: a marker of tumor aggressiveness based on correlation with grade. Mod Pathol 20: 344-351, 2007.

18. Stein T, Cosimo E, Yu X, Smith PR, Simon R, Cottrell L, Pringle MA, Bell AK, Lattanzio L, Sauter G, et al: Loss of reelin expression in breast cancer is epigenetically controlled and associated with poor prognosis. Am J Pathol 177: 232-2333, 2010.

19. Dohi O, Takada H, Wakabayashi N, Yasui K, Sakakura C, Mitsufuji S, Naito Y, Taniwaki M and Yoshikawa T: Epigenetic silencing of RELN in gastric cancer. Int J Oncol 36: 85-92, 2010.

20. Neumann M, Vosberg S, Schlee C, Heesch S, Schwartz S, Gökbuget N, Hoelzer D, Graf A, Krebs S, Bartram I, et al: Mutational spectrum of adult T-ALL. Oncotarget 6: 2754-2766, 2015.

21. Kaur IP, Kaur T, Bhardwaj R, Deol PK, Kakkar V, Vaiphei K and Sanyal SN: Sesamol induces apoptosis by altering expression of bcl-2 and bax proteins and modifies skin tumor development in Balb/c mice. Anticancer Agents Med Chem 16: 1, 2016.

22. Ugland H, Boquest AC, Naderi S, Collas P and Blomhoff HK: cAMP-mediated induction of cyclin $\mathrm{E}$ sensitizes growth-arrested adipose stem cells to DNA damage-induced apoptosis. Mol Biol Cell 19: 5082-5092, 2008.

23. Bleyer A, Viny A and Barr R: Cancer in 15- to 29-year-olds by primary site. Oncologist 11: 590-601, 2006.

24. Lin L, Wang P, Liu X, Zhao D, Zhang Y, Hao J, Liang X, Huang $\mathrm{X}, \mathrm{Lu} \mathrm{J}$ and $\mathrm{Ge} \mathrm{Q}$ : Epigenetic regulation of reelin expression in multiple myeloma. Hematol Oncol: Jun 1, 2016. https:// doi.org/10.1002/hon.2311.

25. Yuan Y, Chen H, Ma G, Cao X and Liu Z: Reelin is involved in transforming growth factor- $\beta 1$-induced cell migration in esophageal carcinoma cells. PLoS One 7: e31802, 2012.

26. Liberman AC, Refojo D, Antunica-Noguerol M, Holsboer F and Arzt E: Underlying mechanisms of cAMP- and glucocorticoidmediated inhibition of FasL expression in activation-induced cell death. Mol Immunol 50: 220-235, 2012.

27. Sen R: Control of B lymphocyte apoptosis by the transcription factor NF-kappaB. Immunity 25: 871-883, 2006.

28. Takahashi N, Tetsuka T, Uranishi H and Okamoto T: Inhibition of the NF-kappaB transcriptional activity by protein kinase A. Eur J Biochem/FEBS 269: 4559-4565, 2002.

29. Parry GC and Mackman N: Role of cyclic AMP response element-binding protein in cyclic AMP inhibition of NF-kappaBmediated transcription. J Immunol 159: 5450-5456, 1997.

30. Lømo J, Blomhoff HK, Beiske K, Stokke T and Smeland EB: TGF-beta 1 and cyclic AMP promote apoptosis in resting human B lymphocytes. J Immunol 154: 1634-1643, 1995.

31. Ivanov VN, Lee RK, Podack ER and Malek TR: Regulation of Fas-dependent activation-induced T cell apoptosis by cAMP signaling: A potential role for transcription factor NF-kappa B. Oncogene 14: 2455-2464, 1997.

32. Zhang L, Zambon AC, Vranizan K, Pothula K, Conklin BR and Insel PA: Gene expression signatures of $\mathrm{cAMP} /$ protein kinase A (PKA)-promoted, mitochondrial-dependent apoptosis. Comparative analysis of wild-type and cAMP-deathless S49 lymphoma cells. J Biol Chem 283: 4304-4313, 2008.

33. Zambon AC, Zhang L, Minovitsky S, Kanter JR, Prabhakar S, Salomonis N, Vranizan K, Dubchak I, Conklin BR and Insel PA: Gene expression patterns define key transcriptional events in cell-cycle regulation by cAMP and protein kinase A. Proc Natl Acad Sci USA 102: 8561-8566, 2005.

34. Moore AR and Willoughby DA: The role of cAMP regulation in controlling inflammation. Clin Exp Immunol 101: 387-389, 1995.

35. Ishida M, Mitsui T, Yamakawa K, Sugiyama N, Takahashi W, Shimura H, Endo T, Kobayashi T and Arita J: Involvement of cAMP response element-binding protein in the regulation of cell proliferation and the prolactin promoter of lactotrophs in primary culture. Am J Physiol Endocrinol Metab 293: E1529-E1537, 2007. 
36. Snijdewint FG, Kaliński P, Wierenga EA, Bos JD and Kapsenberg ML: Prostaglandin E2 differentially modulates cytokine secretion profiles of human T helper lymphocytes. J Immunol 150: 5321-5329, 1993.

37. Hilkens CM, Snijders A, Snijdewint FG, Wierenga EA and Kapsenberg ML: Modulation of T-cell cytokine secretion by accessory cell-derived products. Eur Respir J (Suppl) 22: 90s-94s, 1996.

38. Aandahl EM, Aukrust P, Skålhegg BS, Müller F, Frøland SS, Hansson V and Taskén K: Protein kinase A type I antagonist restores immune responses of T cells from HIV-infected patients. FASEB J 12: 855-862, 1998.

39. Platzer C, Fritsch E, Elsner T, Lehmann MH, Volk HD and Prösch S: Cyclic adenosine monophosphate-responsive elements are involved in the transcriptional activation of the human IL-10 gene in monocytic cells. Eur J Immunol 29: 3098-3104, 1999.
40. Platzer C, Meisel C, Vogt K, Platzer $M$ and Volk HD: Up-regulation of monocytic IL-10 by tumor necrosis factor-alpha and cAMP elevating drugs. Int Immunol 7: 517-523, 1995.

41. Gaiano N and Fishell G: The role of notch in promoting glial and neural stem cell fates. Annu Rev Neurosci 25: 471-490, 2002

42. Brai E, Marathe S, Astori S, Fredj NB, Perry E, Lamy C, Scotti A and Alberi L: Notch1 regulates hippocampal plasticity through interaction with the Reelin pathway, glutamatergic transmission and CREB signaling. Front Cell Neurosci 9: 447, 2015.

43. Rogers JT, Rusiana I, Trotter J, Zhao L, Donaldson E, Pak DT, Babus LW, Peters M, Banko JL, Chavis P, et al: Reelin supplementation enhances cognitive ability, synaptic plasticity, and dendritic spine density. Learn Mem 18: 558-564, 2011. 